\title{
El trabajador del caucho y la representación narrativa
}

\author{
Rubber tapper and narrative representation \\ $O$ seringueiro e a representaçao narrativa
}

\section{Ana Pizarro}

universidad de SANTIAGo DE CHILE (USACH), CHILE

Profesora del Instituto de Estudios Avanzados, Universidad de Santiago de Chile. Doctora en Letras, Universidad de París, La Sorbona. Autora de los libros: De ostras y caníbales. Ensayos sobre la cultura latinoamericana (Editorial Universidad de Santiago, 1994); La luna, el viento, el año, el día (Novela) (Fondo de Cultura Económica, 1994); El sur y los trópicos. Ensayos sobre cultura latinoamericana (Universidad de Alicante, 2004); Amazonía: el río tiene voces (Fondo de Cultura Económica, 2009). Compiladora de América Latina: palavra, literatura e cultura, Vols I, II y III (Memorial de América Latina, 1994).Correo electrónico: ana.pizarro@usach.cl

\footnotetext{
Artículo de Reflexión

Artículo redactado en el marco del proyecto Fondecyt Chile $N^{\circ} 1130739$ año 2013, cuatro años. Investigadora responsable: Ana Pizarro, Universidad de Santiago de Chile. Elaborado a partir de una ponencia presentada en el Colloque International Les changements dans les modèles culturels du travail en Afrique: Une approche comparative, FASTEF/UCAD, Dakar, Senegal, 5 al 7 de diciembre de 2011. Documento accesible en línea desde la siguiente dirección: http://revistas.javeriana.edu.co 


\section{Resumen}

En ciertas ocasiones, la narrativa puede entregar una percepción reduccionista de los trabajadores. Es el caso de la novela de Mario Vargas Llosa El sueño del celta (2011). En su discurso, el escritor peruano explica eventos históricos relacionados con los trabajadores del caucho en los cuales participó el irlandés Roger Casement. El escritor alude a la investigación publicada acerca de los problemas enfrentados por los trabajadores. Sin embargo, no logra advertir que estos trabajadores son los mismos en el Congo y en la Amazonía: solamente trabajan, carecen de otra dimensión y nunca se convierten en verdaderos seres humanos. Hay, pues, en esa narrativa reduccionista, un segundo discurso occidentalizante.

Palabras clave: historicismo; narrativa; caucho

\section{Abstract}

Sometimes narratives can give a reductionist perception of workers. It is the case of the novel of Mario Vargas Llosa $E l$ sueño del celta (2011). In his discourse, the Peruvian writer explains historic events of rubber workers in which Irish Roger Casement participated. Vargas Llosa refers to a published research about the problems faced by the workers. However, he fails to notice that these workers are the same in Congo and in Amazonia: they only work, they have no other dimension and never become true human beings. Therefore, there is in this reductionist narrative an occidentalist discourse.

Keywords: historicism; narrative; rubber

\section{Resumo}

Às vezes, a narrativa pode oferecer uma percepção reducionista dos trabalhadores. É o caso do romance de Mario Vargas Llosa, El sueño del celta/O sonho do celta (2011). Em seu discurso, o escritor peruano explica acontecimentos históricos relacionados aos seringueiros nos quais participou o irlandês Roger Casement. O escritor se refere à pesquisa publicada sobre os problemas enfrentados pelos trabalhadores. No entanto, não consegue perceber que estes trabalhadores são os mesmos no Congo e na Amazônia: somente trabalham, carecem de outra dimensão e nunca se convertem em verdadeiros seres humanos. Existe, portanto, nessa narrativa reducionista, um segundo discurso ocidentalizante.

Palavras-chave: historicismo; narrativa; borracha

RECIBIDO: 29 DE MARZO DE 2014. APROBADO: 17 DE ABRIL DE 2014. DISPONIBLE EN LÍNEA: 15 DE ENERO DE 2015

\section{Cómo citar este artículo:}

Pizarro, Ana. "El trabajador del caucho y la representación narrativa". Cuadernos

de Literatura 19. 37 (2015); 313-327. doi:10.11144/Javeriana.CL19-37.tcrn 
TENEMOS FRENTE A nosotros el relato de una indígena tikuna de la zona llamada del Trapecio, en la frontera de Brasil con Colombia, en la Amazonía. Hemos registrado su testimonio en vídeo (Pizarro y Sepúlveda, 2002). Tenemos al lado nuestro también El sueño del celta, la novela en la que Mario Vargas Llosa (2010) aborda el tema de los trabajadores del caucho en África y en la Amazonía. Uno al lado del otro, los documentos no logran dialogar. Esto nos lleva a algunas reflexiones acerca de las relaciones entre historicismo, ficción y memoria. Para desarrollarlas presentaremos el contenido de un mito central de las culturas amazónicas, además de otras formas de su imaginario complejo, en el caso brasileño, e informaremos sobre el drama del Putumayo para luego referirnos a dimensiones de la vida cotidiana que expresan la complejidad de sus identidades y finalmente observar que el texto de Vargas Llosa tiene una mirada homogeneizadora que reduce la pluralidad del referente.

En la grabación documental, la mujer indígena no habla otra lengua que la tikuna y su hijo la traduce, pero en su relato no interviene sólo el lenguaje oral sino también la gestualidad, la vestimenta occidental con elementos de su cultura y las inflexiones tenues de su voz. Ella ha viajado a Belém do Pará y seguramente es la primera vez que viene a la gran ciudad. En su narración amazónica, ella expone el que se llama en el área el "mito de la Cobra Grande". Para los tikuna, se trata del relato originario de su pueblo y está marcado por el lenguaje del cuerpo, que expresa seriedad.

La Cobra Grande tiene también otros nombres: es la Boiúna, la Mae d'Agua; a veces es Cobra Norato, pero en general éste es hijo de la Boiúna y está signado por la bondad. Este personaje mata a su hermana, cuyo signo, opuesto, es la maldad - contraposición común en estas narraciones-, para volverse hombre. Se trata un mito cosmogónico que no se encuentra en el estadio primero de la creación, en donde aparece un dios que luego se vuelve "ocioso", sino en el mito de origen de lo humano, es decir, se trata de un mito antropogénico, otra instancia del proceso de creación. En el origen, la gran serpiente fue vomitando - el vómito es un acto creador en la medida en que se expele fuera de sí un cuerpo extraño y así se da vida - a las distintas etnias que poblaron el mundo, situándolas en uno de los niveles del universo. En la versión dessana, la serpiente resulta de la transformación del Tercer Trueno, es la corporización de lo etéreo (Krüger 66). Las simbolizaciones de la serpiente son múltiples en toda la Amazonía y, en realidad, están presentes en muchas cosmogonías a nivel universal, pero nos referimos ahora a la zona del Alto Amazonas y del Río Negro, donde representa la renovación de la vida, el agua - por lo escurridiza - y el mismo río en el que vive, adoptando la forma de un barco, del cual sale a menudo. El cambio de piel 
alude a la juventud permanente puesto que, vuelta sobre sí misma —como en el caso del Uróboros-, la serpiente puede significar el tiempo que retorna sobre sí, entre tantas otras simbolizaciones.

Los trabajadores del caucho, los indígenas que hicieron y hacen aún la extracción en la zona del piedemonte andino, fueron los grupos étnicos del área regada por el Río Negro, el Solimoes, el Putumayo, el Caquetá, el Madre de Dios, el Juruá, el Muru, entre otros afluentes del amplio tejido fluvial que da forma en esa zona a la cuenca inicial del Amazonas. Las peores historias conocidas con respecto al trabajo esclavo de los indígenas surgen de esa área geográfica. Ellas se refieren al período de fines del siglo XIX e inicios del XX, que es el de los mayores "barones del caucho": Julio César Arana, Carlos Fermín Fitzcarraldo, Nicolás Suárez, en la parte hispana, y algunos otros "coronéis do barranco" de la parte lusoamericana que dejaron triste recuerdo, marcando la memoria indígena de la región con un antes y un después de los hechos. Esta memoria histórica a veces incluso bloquea la memoria mítica para asumirse como el comienzo de la narración. Citando a Jean-Pierre Chaumeil, Priscila Faulhaber observa respecto de este punto de inflexión en la memoria grupal que "... 'é o tempo do caucho' que imprime o ponto de articulação entre mito e história oral. Este tempo representa uma espécie de retorno a um 'ponto zero', a origen da 'história' para esses grupos que, mais que outros, sofreran os efeitos devastadores de trabalho forçado nas explorações caucheiras..." (149). ${ }^{1}$

La historia de la extracción del caucho en la Panamazonia tiene un signo de negatividad, de oscuridad y de silenciamiento. Es apenas en las últimas décadas que han aflorado algunos documentos reeditados y que los historiadores del área han comenzado a investigar el auge cauchero que tuvo lugar hacia 1900. Un ensayo clásico del período en la parte brasileña, como es el texto À margem da história, la publicación póstuma de Euclides da Cunha, de 1909 (2003), nos entrega el comienzo de una épica que no alcanzó a concretar, después de realizar un viaje oficial a la zona para delimitar fronteras en el Alto Purus. También se refiere a lo acontecido La Vorágine de José Eustasio Rivera, de 1924 (1985), autor que desempeñaba la misma función en la parte colombiana y que en esta novela entra en la profundidad del universo cauchero a través de un personaje citadino. Estos textos fueron escritos al calor mismo de los hechos históricos. Pero también existen otros en diversos países del área de explotación cauchera: Caucho del boliviano Diomedes de Pereyra, de

$1 \quad$ "...'es el tiempo del caucho' que marca el punto de articulación entre mito e historia oral. Este tiempo representa una especie de retorno a un 'punto cero', al origen de la 'historia' para esos grupos que, más que otros, sufrieron los efectos devastadores del trabajo forzado en las explotaciones caucheras...". 
1938; Seringal, del brasileño Miguel Jeronymo Ferrante, de 1972; y, más contemporáneamente, Fordlandia del argentino Eduardo Sguiglia, de 1997. Hoy, esta historia también ha tenido difusión con la reciente novela de Mario Vargas Llosa El sueño del celta, en donde se trata de seguir la historia de Roger Casement, cónsul del gobierno británico en Brasil, quien hizo para su gobierno informes devastadores sobre quiénes dirigían la extracción del caucho tanto en el Congo alrededor de 1903 como en la Amazonía peruana en torno a 1911. Nos interesa observar en esta última novela, por su amplia difusión, la imagen ficcional del trabajador del caucho que, no siendo el tema central de la novela, ocupado por otras cuestiones de la vida de Sir Roger Casement, tiene importancia en el relato. Pero nos interesa también, y sobre todo, observar que el autor desarrolla una perspectiva simplificadora de los trabajadores del caucho que homogeneiza a los personajes africanos y a los trabajadores amazónicos.

En torno a los llamados "sucesos del Putumayo", "matanzas del Putumayo" o "escándalos del Putumayo" se escribieron informes, diatribas, libros, se alegó en las cortes inglesas. Se trataba, en este caso, de la puesta en evidencia, por parte de un periodista peruano, Benjamín Saldaña Roca, y de un joven ingeniero ferroviario norteamericano, Walter Hardenburg, de las condiciones de trabajo esclavo en que vivían y morían los indígenas de los establecimientos llamados "La Chorrera" y "El Encanto", de propiedad del peruano Julio César Arana en la entonces disputada frontera colombo-peruana. Funcionarios de alto rango del gobierno inglés también tenían en esa explotación sus capitales. De allí el interés de Inglaterra, frente al escándalo internacional, de tratar de defender su imagen, ya ampliamente ensuciada por su colonialismo. Quedó en evidencia todo un sistema de explotación con diferentes grados de poder y de crueldad y, por lo tanto, con distintos tipos de verdugos, en que los indígenas eran traídos de sus aldeas para el trabajo esclavo. Había allí, cotidianamente, robo, tortura, estupro, crimen. Se calcula que las víctimas de los asesinatos fueron 30.000 indígenas, fundamentalmente de las etnias bora y huitoto. Respecto de las controversias suscitadas en torno de estos hechos, afirma un historiador:

El debate posterior a las denuncias públicas sobre lo que pasaba en los establecimientos caucheros gestionados por The Peruvian Amazon (heredera de la Casa Arana) entre el Putumayo y el Caquetá, área cuya propiedad se disputaban entonces Colombia y Perú, presenta un escenario en el que se manipulan conceptos como patria, regionalismo, centralismo, civilización y progreso, entre los más importantes. Mientras en la otra cara de la moneda, la que corresponde a las víctimas, los indígenas aparecen como seres peligrosos y caníbales, a quienes los civilizadores caucheros, tratan de ayudar para que salgan de su mundo de tinieblas (Chirif 10). 
Es posible recuperar, apenas hoy y fragmentariamente, el relato de lo sucedido mediante algunos documentos, informes, fotografías y testimonios familiares. En la parte brasileña, aquel otro lugar separado por fronteras difusas en medio de la selva, la situación y las condiciones de vida de los seringueiros no fue diferente. Allí se documenta el sistema de aviamento, mediante el cual el patrón les vendía las mercaderías básicas para la sobrevida en la selva a precios elevadísimos, endeudándolos de por vida e incluso en forma hereditaria. Había castigos corporales por no cumplir lo esperado por los capataces, que se sumaban a maltratos de todo tipo dentro de una vida mísera que llevó a denominar a esta zona de la Amazonía el "infierno verde". Se trataba de otra forma de esclavitud en el siglo XX, en medio de la selva. En un reporte de la época sobre la situación indígena, en Perú, uno de los informantes - el Juez Paredes- apunta una curiosidad lingüística: "a un rifle, por ejemplo, le dicen 'yoveca', que significa 'la voz del blanco" (Chirif 173).

No obstante, un investigador brasileño del período actual dimensiona en los trabajadores del caucho del río Muru, a partir de una experiencia personal, otra faceta que nos interesa especialmente, ya que propone:

Analisar as experiencias de vida de um conjunto disperso de homens, mulheres e crianças, que se identifiquem enquanto trabajadores da mata pelo fato de partilharem o mesmo ambiente e construir um modo de viver comum; vivenciarem conflitos semelhantes com os patroes, experimentarem formas de dominaçao e resistencia individual e coletiva que se dao em varias dimençóes, nao debe implicar na petrificaçao de seus desejos, temores, paixoes, preferencias, religiosidades, moral e sonhos ${ }^{2}$ (Albuquerque 56).

Hay diferencias entre las distintas funciones, trabajos y luchas de los trabajadores rurales, que hace a distintos modos de encarar el mundo. El investigador agrega:

No espaço de construçao-reconstruçao quotidiana de sus culturas, entre os trabalhadores do rio Muru é forte a presença de seres como o mapinguary, o caboquinho e a mae da mata, que surgem nos relatos e histórias contadas e recontadas por diferentes geraçoes. Esses seres ganhan concreticidade no

2 "Analizar las experiencias de vida de un conjunto disperso de hombres, mujeres y niños, que se identifican como trabajadores de la selva por el hecho de compartir el mismo ambiente y construir un común modo de vida, vivenciar conflictos semejantes con los patrones, experimentar formas de dominación y resistencia individual y colectiva que se dan en varias dimensiones, no debe implicar la petrificación de sus deseos, temores, pasiones, preferencias, religiosidad, moral y sueños". 
silêncio, na solidao, nos ruídos, assobios, visoes, cantos, nas sombras e escuridao da mata $^{3}$ (Albuquerque, 57 ).

Lo interesante es la percepción de la creación identitaria permanente en el nivel de los imaginarios, pues el investigador se refiere a una "cultura seringueira" que sería la expresión y que, al mismo tiempo, le entregaría dimensiones fundamentales al perfilamiento de las vidas de los trabajadores del caucho, a la construcción de su cotidiano. En efecto, esta dimensión en general no es contemplada por los historiadores y es, por cierto, difícil de recomponer, perfilándose como una tarea de la novela histórica.

Es en este campo, el de los imaginarios y la construcción de la vida a partir de ellos, que se encuentra centralmente el relato de la Cobra Grande, de Cobra Norato. El relato mítico pasa, entonces, al espacio de la vida cotidiana, alimentando decisiones y explicando lo inexplicable, pero también generando emociones y sentimientos, organizando la vida, perfilando destinos individuales y colectivos. Se sitúa en aquel nivel de la cultura popular donde tiene lugar, en la oralidad, el encuentro de un habla que direcciona su comunicación y de otra que la recibe, la experimenta, la reordena o la acepta, generando ese espacio que constituye la carnadura de la historia: la conversación. En efecto, esa interacción entre el yo y el tú construye una "historicidad compartida", apunta Leonor Arfuch con enorme perspicacia, agregando que "es en el diálogo con otros - que de alguna manera se hacen responsables de nosotros - que va tomando forma y sentido el acontecer, en sus mínimos incidentes y en la común preocupación existencial, en la anécdota, el consejo, el chiste, el chisme, el comentario..." (Arfuch 25). Ese ordenamiento y puesta en sentido de la vida, dice la autora, tiene una orientación valorativa en donde ningún relato es inocuo, en donde el relato impacta la vida del otro más allá de la co-referencia a un mundo en una situación existencial: "en ese 'ser tocado' por la experiencia del otro hay mucho del aprendizaje del vivir y también de la confrontación subjetiva de los propios límites" (Arfuch 23).

La importancia de la construcción de lo cotidiano, en dimensiones que no se consideran sino cuando están consignadas, escritas - la autoridad de la "ciudad letrada" (Rama 2004) - , y que, dejando en un plano secundario la consideración empírica de datos, fechas, números y estadísticas, es la que recupera la

3 "En el espacio de construcción-reconstrucción cotidiana de sus culturas, entre los trabajadores del río Muru es muy fuerte la presencia de seres como 'mapinguary', el 'caboquinho' y la 'madre de la selva', que surgen en los relatos e historias contadas y recontadas por diferentes generaciones. Estos seres se vuelven más concretos en el silencio, la soledad, en los ruidos, los silbidos, visiones, cantos, en la sombra y la oscuridad de la selva". 
humanidad de los sujetos en cuestión, su manera de sentir y proyectar, su modo de amar, su sentido del placer y del dolor: su "estética de la intimidad" (Amaro 2009). Es lo que podemos recuperar a través de los espacios más cercanos, esa esfera que ha sido dejada de lado por el relato histórico y en la cual la nueva historia cultural ha abierto brechas para la indagación.

He aquí algunos de los gestos que implican al otro. Son gestos de diversa intensidad, ritmo e interpelación, pero que van construyendo un tejido de significaciones en donde hay fragmentariamente comunidad de códigos, similitud de experiencias, diferentes y similares intensidades emotivas.

El devenir del grupo en la dimensión cotidiana de su historia es el que, aunque ellos tuvieran relevancia en la construcción del discurso histórico, no estaría presente en su consignación. No habrá escritura para ello. Anotemos algunos parlamentos sobre el relato que nos ocupa, los que Faulhaber incorpora en su análisis con el fin de aproximarse a la imbricación entre "discurso argumentativo" y "relaciones sociales":

$R(1)$ - Eu estaba na beira do rio, no Auti-Paraná e vi, num canto, uma embarcação... mas não era... Era Sereia, Cobra. Sumia e eu não sabia para onde ia. Eu conto, e muita gente diz que eu tinha sonhado com ela. Era uma embarcação demais grande... porque todo o mundo via, era só olhar... aí via... era Cobra Grande. Encante... ${ }^{4}$ (Faulhaber 163).

R (7) - Na boca da noite, aparece mesmo. Outra noite eu vi. Um Navio... Foi chegando, bem ali no canto, no meio do rio... Era um barracão, que tinha bastante... Vinha baixando,e vinha aparecendo aqueles artigos, aparecendo da cobertura... Ai sumiu... Eu pensei: que diabo é ese tamaño barracão, sumindo assim... Nao tinha mais não, afundou... Aí eu lembrei isto é Encante, Cobra....! (Faulhaber 164).

En las conversaciones cotidianas no aparece sólo la Cobra Grande sino también otros seres que pueblan la vida: Curupira, que cuida la floresta y tiene a

"R (1)- Yo estaba en la orilla del río, en el Auti-Paraná, y vi, en un rincón, una embarcación... pero no era... Era Sirena, Serpiente. Se sumergía y yo no sabía para donde iba. Yo lo cuento y mucha gente me dice que yo soñé con ella. Era una embarcación muy grande... porque toda la gente la veía, bastaba con mirar... ahí estaba...era la Cobra Grande. Encantamiento...".

"En la boca de la noche, allí aparece. La otra noche yo la vi. Un Navío... Fue llegando ahí, en una esquina, en medio del río... Era un barracón, que tenía bastante... Venía bajando y venían apareciendo esas cosas, apareciendo en la cubierta... Entonces se sumergió... Yo pensé: qué diablo es ese tremendo barracón, hundiéndose así... Ya no estaba, se hundió... Entonces me acordé: esto es un Encantamiento, ¡Cobra...!". 
menudo los pies al revés; el Boto, que seduce a las jóvenes para luego sumergirse en el río; construcciones del imaginario histórico de la zona con raíces en distintas culturas, apropiaciones de la cultura europea, imágenes transformadas de la cultura africana, pervivencias de la cultura indígena. Ellas hacen la intermediación entre los hombres y el mundo sobrenatural, formando parte de los sistemas simbólicos que organizan su experiencia en lo cotidiano. Como entidades del orden mítico, estos relatos permiten realizar la construcción de la vida y del sentido que los habitantes de la floresta le otorgan a la existencia en una relación central con el espacio en que viven: el agua, los árboles, los pájaros, las bestias. No obstante, la construcción de los imaginarios tiene, además, otros espacios propios en los trabajadores del caucho.

En la parte brasileña, esto es, en la gran extensión amazónica, gran parte de los seringueiros de comienzos del siglo veinte, en el período de auge de la industria cauchera, fueron traídos mañosamente del nordeste brasileño, que vivía entonces sus peores períodos de sequía. Vinieron engañados por la posibilidad de volver al nordeste con dinero para sus familias, buscando una sobrevida que la sequía de su región no les permitía. En el trayecto del nordeste a Manaos, y de Manaos al interior de la selva hasta las caucheras, ya estaban endeudados y su destino era el trabajo esclavo de los seringales, el sistema de aviamento, el dolor de la distancia, la soledad.

Sin embargo, estos trabajadores trajeron consigo un mundo tradicional del nordeste que se expresa en oralidad, en diálogos poéticos en contrapunto llamados "desafíos", en lecturas colectivas de impresos artesanales, en relatos de cordel. Ellos trajeron los relatos más queridos a su vida en el lugar de la sequía y los hicieron reconstruirse en el espacio de la floresta. El enfrentamiento de estos dos mundos tan diferentes y geográficamente opuestos implicaba ya, para ellos, una fuerte forma de violencia en los imaginarios. Entonces, reasentaron allí los relatos de su origen y revivieron, por ejemplo, las historias de Lampião y María Bonita o la de Juvenal y el Dragão, entre tantas. Si bien había historias propias del sertón, la imaginación también se llevaba allí, muy lejos del lugar, las historias del Rey Arturo y los Doce Pares de Francia, y lo mismo ocurría por ejemplo con la historia de la Donzela Teodora, una joven árabe que adquiere sabiduría y enfrenta al poder de los letrados del Rey Almançor.

Eran "momentos de sociabilidade permeada pelo código escrito e um esforço, por parte dos aprendizes, na aquisiçao da leitura e da escrita utilizando a creatividade para a consolidaçao de esta prática" (Silveira 22). Desde comienzos

6 "Momentos de sociabilidad permeada por el código escrito y un esfuerzo, de parte de los aprendices, en la adquisición de la lectura y de la escritura utilizando la creatividad para la consolidación de esta práctica". 
del siglo XX llegaban a los seringales folletos de cordel, publicados por una imprenta que se dedicaba a este género en Belém, Guajarina, como llegarían más tarde la revista Manchete, los almanaques - que no sólo eran relato sino que tenían además una función utilitaria-, y la radio, cuya audición se realizaba en forma colectiva. Respecto de la relación social generada por esta práctica en el segundo período del caucho en Brasil, es interesante lo que Lindalva Marques, una habitante del Acre cuya familia migró del nordeste, explica a propósito de una vecina contadora de historias:

(...) ela era uma pessoa muito inteligente, tá? Porque para lé e contá uma história daquela e até fazer certa encenação, né? Aquela... Que tem pessoa que conta uma história sem graça e tem aquela pessoa que conta como se tivesse representando e ela contaba como representasse. E, quando ela não quería contar história para gente, já tava cansada, ela dizia: "não, hoje eu vou contar a história da velha cachorrosa". Aí todo o mundo corria embora para... era história de assombração ${ }^{7}$ (en Silveira 22).

Los elementos y situaciones a que apuntamos hablan de una complejidad de los imaginarios, las sensaciones, las emociones de los trabajadores del caucho, de su pluralidad, sus miedos, y también de sus formas de relacionarse.

La escritura de la historia de los seringales, en general, nos entrega un relato que tiene la frialdad de las cifras, de los mecanismos de opresión, el recuento de los tormentos. La gran interrogante que esto levanta es: ¿ cómo dar vida al análisis de la sociología o de la historia para lograr transmitir, aunque no sea más que en fragmentos, la vida del ser humano que trabaja en los seringales? ¿Basta con la austeridad del documento para compartir con el receptor del análisis la vitalidad, la belleza, los modos de soñar, de disfrutar, los modos del amor -el amor filial, el amor de pareja, la amistad — de los trabajadores de la seringa? ${ }_{\mathrm{C}}$ Necesitamos ir más allá en un análisis histórico factual y, a través de los momentos que podemos capturar de la vida cotidiana, apuntar a la formación y al movimiento de los imaginarios? Seguramente es allí en donde logramos encontrar el tropismo, el gesto mínimo, la pequeña manifestación de la vida en donde es posible leer mucho más, así como deconstruir muchas veces lo concreto, apuntando a la observación del

“(...) ella era una persona muy inteligente, ¿ivio? Porque para leer y contar una historia de aquellas e incluso hacer una representación $\mathrm{c}^{\text {no? }}$. Aquella... Que hay personas que cuentan una historia sin gracia y hay personas que cuentan como si estuviesen representándola, y ella contaba como representando. Y cuando ella no quería contar historias para los demás, estaba cansada, decía: 'no, hoy voy a contar la historia de la vieja perra'. Entonces toda la gente se iba corriendo porque... era una historia de prodigio, de asombro". 
funcionamiento simbólico. Porque allí estará la "Historia", mucho más que en la de una sociedad vista por el "historicismo" del que hablaba Walter Benjamin. Mucho más que en la historia del funcionamiento del aparato económico que reduce a la esclavitud, aquí estará el ser humano, el que merece tener el mayor sentido y presencia en nuestra búsqueda del conocimiento.

Como señalábamos anteriormente, junto a las narraciones orales o de cordel, la historia de los trabajadores del caucho ha sido objeto de narraciones actuales de la literatura docta, referidas, en general, al período que nos ocupa, a inicios del siglo XX. La Vorágine, del colombiano José Eustasio Rivera, es considerado uno de los grandes relatos en Hispanoamérica, y gran parte de su virtud consiste en haber hecho de los trabajadores del caucho personajes creíbles. De aparición reciente, Fordlandia, del argentino Eduardo Sguiglia, narra la frustrada operación de Henry Ford para formar parte de la operación cauchera. Existen otros relatos relativos al período, desde dentro y fuera de la Amazonía. Pero El sueño del celta, novela de Mario Vargas Llosa publicada el año en que le fue otorgado el Premio Nobel de Literatura (2010), es una de las más recientes en tener relación con el desarrollo que hemos hecho más arriba. A ella nos queremos referir.

En esta novela, el escritor peruano sigue la historia de Sir Roger Casement, un funcionario del gobierno británico para los asuntos del caucho, primero en el Congo, alrededor de 1903, y luego en la Amazonía peruana, en torno a 1911. El personaje, histórico da la espalda a la corona y reivindica su origen irlandés en el levantamiento en contra de los ingleses. Finalmente, muere en manos de ellos.

Queremos apuntar a una debilidad del relato, porque lo que el lector percibe, más allá de la biografía de Casement y los devaneos sobre su homosexualidad, es un relato brumoso. Aquí aparecen los trabajadores del caucho, los seringueiros, como figurines que son objeto de maltrato. Pero cuando tratamos de aprehenderlos, son personajes sin vida, de una sola dimensión, en donde la función que desempeñan parece más importante que su misma existencia. Su representación no tiene latencia ni intensidad: son trabajadores del caucho y el lector no puede identificarlos, porque los trabajadores del Congo parecen ser los mismos que los de la Amazonía. Podemos observar, por ejemplo, la escritura de Vargas Llosa en relación al Congo:

"No vi llorar a nadie en Walla", pensaría después Roger Casement. Tampoco oyó a nadie quejarse. La aldea parecía habitada por autómatas, seres espectrales que ambulaban en el claro, entre la treintena de chozas de varillas de madera y techos cónicos de hojas de palma, de un lado al otro, desbrujulados, sin saber dónde ir, olvidados de quiénes eran, dónde estaban, como si una maldición hubiera caído sobre la aldea convirtiendo a sus pobladores en fantasmas (98). 
En este fragmento podríamos consentir que se trata de la narración en la mirada de su protagonista, Casement, lo que explicaría su distanciamiento. Sin embargo, cuando aparece la voz del narrador, la perspectiva no es menos externa ni fría, al transmitir la descripción que hacen los informes históricos:

Roger cumplió con su trabajo. Interrogó a cada uno y a cada una de los pobladores, escuchándoles repetir lo que ya había oído y oiría después muchas veces. Aquí también, en Walla, se sorprendió de que ninguno de esos pobres seres se quejara de lo principal: ¿con qué derecho habían venido esos forasteros a invadirlos, explotarlos y maltratarlos? Sólo tenían en cuenta lo inmediato: las cuotas. Eran excesivas, no había fuerza humana que pudiera reunir tanto caucho, tantos alimentos y ceder tantos brazos. Ni siquiera se quejaban de los azotes y los rehenes. Sólo pedían que se les rebajaran un poco las cuotas para poder cumplir con ellas y de este modo tener contentas a las autoridades con la gente de Walla (98).

Evidentemente, el relato impacta. Pero su fuerza reside en la brutalidad histórica de la explotación colonial, en este caso, más que en el talento narrativo de la construcción del discurso o en el eventual perfil de humanidad que se entrega de las víctimas. Es un relato bien intencionado, ciertamente, pero lo que perturba es la fuerza de la "crónica roja", no la virtualidad de la composición estética. De pronto, el sujeto de la enunciación es confuso y no sabemos si es la voz del funcionario inglés, con su distanciamiento y racionalidad, o la del escritor peruano, cuyo distanciamiento parece aún mayor. No hay seres humanos individuales entre los trabajadores, son grupos, masas en movimiento, en situación de víctimas. La tematización de la historia inscrita en el informe de Roger Casement que escribe el narrador peruano se enmarca en una representación de los trabajadores del caucho dentro de la perspectiva de una lógica tradicional, exterior, eurocéntrica. Esto podría ser normal para el período en que escribe Casement, pero no lo es para una perspectiva actual del mundo africano ni indígena amazónico, porque aquí los trabajadores del caucho son maquetas, figuras vistas desde el exterior. El relato está hilvanado partir de informaciones históricas que aparecen en los textos clásicos sobre el tema. En el caso de la parte correspondiente al trabajador amazónico, la perspectiva es similar. Observemos:

Cerca de ochocientos ocaimas llegaron a La Chorrera a entregar las canastas con las bolas de caucho recogido en los bosques. Después de pesarlas y almacenarlas, el subadministrador de La Chorrera señaló (...) a los veinticinco ocaimas apartados del resto que no habían traído la cuota mínima de jebe -látex o caucho- a que estaban obligados. Macedo y Loaysa decidieron 
dar una buena lección a los salvajes. Indicando a sus capataces - los negros de Barbados - que tuvieran a raya al resto de los ocaimas con sus máuseres, ordenaron a los "muchachos" que envolvieran a los veinticinco en costales empapados de petróleo. Entonces les prendieron fuego. Dando alaridos, convertidos en antorchas humanas, algunos consiguieron apagar las llamas revolcándose sobre la tierra, pero quedaron con terribles quemaduras (Vargas Llosa 156-157).

Se trata del relato de un gran narrador, como ha sido reconocido internacionalmente. Pero como en todos los casos de escritores de valor, su producción no es homogénea, y creo que éste es un momento de debilidad en su escritura. Aquí la narración careció de la tensión interna que ha tenido en otros grandes momentos; la debilidad en la construcción de estos personajes hace que el efecto del horror que experimentan sea más información que estremecimiento. Se instala en el relato una visión dicotómica, bipolar, más propia de la guerra fría que de la percepción plural en distintos ámbitos que se tiene hoy.

Esto se da porque la elaboración narrativa es escasa y reproduce una perspectiva de lógica jerárquica. El narrador no los transmite como seres humanos. En esto coincido con la investigación de Inger Enkvist, quien afirma que " $\mathrm{El}$ sueño del celta tiene algo de panfleto más que de novela. Los indígenas no hablan y generalmente no tienen nombre, sino que están presentes sólo como víctimas".

En este sentido, a pesar del momento en que fue escrito y presentado al Parlamento Inglés (1912), en el texto de Roger Casement percibimos un narrador perturbado detrás de las enumeraciones del informe y las cartas que tiene momentos de mucha mayor eficacia a nivel de discurso estético. En este caso, quien escribe se cuestiona, indaga, transmite su sospecha, interroga a uno y otro, transmite su intranquilidad, o como cuando afirma, luego de presentar una declaración, que "esta imagen es verdadera; descripciones detalladas de este tipo de azote me fueron presentadas una y otra vez por hombres que habían sido empleados para este trabajo" (90).

¿Cuál es entonces la virtualidad del escritor frente al "escribiente", recordando la dupla de conceptos barthesianos? ¿Es sólo la información que, por lo demás, es una información existente? ¿Acaso la virtualidad estética no consiste en que, en lugar de relatarnos la hoguera, nos debe entregar el fuego mismo?

Aquí se sitúa el problema: el historicismo no puede dar cuenta sino de una mirada externa. No logra "apoderarse de la auténtica imagen histórica" (Benjamin 137). Es por eso que, cuando uno se pregunta con quien simpatiza el autor en una aproximación de este tipo, la respuesta es, sin duda, "con el vencedor" (ídem). 
En este caso, el vencedor desde luego no es necesariamente el barón del caucho, sino que es el hombre blanco, el occidental frente al indígena, mestizo o cholo. Es decir, el narrador presenta una imagen lejana y cosificada de los personajes, quienes toman una sola dimensión, la del personaje-víctima, poniendo en evidencia una distancia que dificulta empatizar al lector con éste o, incluso, distinguir en este caso entre los trabajadores del caucho africanos o los amazónicos: ambos tienen un perfil similar.

En este sentido, no hay una sola Historia sino muchos relatos que significan de manera diferente los mismos acontecimientos. En el caso del autor de la novela a la que nos referimos, es evidente que construye una narrativa que pone en evidencia atrocidades cometidas por los dueños de las propiedades caucheras, los llamados barones del caucho, y, en este caso, las de la empresa de Julio Arana y su grupo de poder. Esto es importante. Se trata de una historia, como decíamos, hasta ahora poco difundida y de una polémica cuyos textos, en buena parte, recién empiezan a ser publicados para una audiencia mayor (Pizarro 117 y ss.), siendo conocidos hasta hace poco sólo por algunos especialistas. Sin embargo, su relato forma parte de un conjunto de prácticas representacionales que participan en la producción de concepciones del mundo. Así, tratándose de una visión occidentalizada, que petrifica el universo interno de los trabajadores de la selva, esta perspectiva, apunta Fernando Coronil, interviene, aunque sea en forma inconsciente, en la reproducción de las actuales asimetrías de poder.

Esta es justamente la razón de por qué un real acercamiento entre historia y literatura debería permitir ir más allá en la dimensión humana. Es decir, por una parte, como apuntaba Michel de Certeau, se trataría de concebir "a cada verdadero historiador" como un "poeta del detalle" (94). O bien, decimos, por otra, al escritor de narrativa histórica con la capacidad estética de transmitir lo que el pintor Roberto Matta llamaba, con su genialidad, un "êtreur": ${ }^{8}$ un ser que está siendo.

\section{Obras citadas}

Albuquerque, Gerson Rodrígues de. Trabalhadores do Muru, o rio das cigarras. Rio Branco: EDUFAC, 2005.

Amaro Castro, Lorena, ed. Estéticas de la intimidad. Santiago: Instituto de Estética-PUCC, 2009.

8 Una escultura de Matta presentada en la exposición de la Galería Der Brücke en Buenos Aires (agosto-octubre, 1990) tenía por título "L'Êtreur": la figura se hacía en la medida en el espectador la contorneaba. 
Arfuch, Leonor. "Íntimo, privado, biográfico: espacios del yo en la cultura contemporánea". Ed. Lorena Amaro Castro. Estéticas de la intimidad. Santiago: Instituto de Estética-PUC, 2009. 17-28.

Benjamin, Walter. "Sobre el concepto de historia". Estética y política. Trad. de Joaquín Bartoletti y Julián Fava. Buenos Aires: Las Cuarenta, 2009. 129-152.

Casement, Roger. "Carta Nº. Del cónsul General Casement a Sir Edward Grey. Londres, 17 de marzo de 1911". Eds. Cornejo Chaparro, Manuel y Alejandro Parellada. Libro Azul Británico. Informes de Roger Casement y otras cartas sobre las atrocidades en el Putumayo. Lima: CAAAP-IWGIA, 2012,74-120.

Certeau, Michel de. La escritura de la historia. México: Universidad Iberoamericana, 1999.

Chirif, Alberto. "Imaginario sobre el indígena en la época del caucho". Eds. Alberto Chirif y Manuel Cornejo Chaparro. Imaginario e imágenes de la época del caucho: Los sucesos del Putumayo. Lima: CAAP, 2009, 9-35.

Coronil, Fernando. "Más allá del occidentalismo: hacia categorías históricas no imperiales". Casa de las Américas 206 (La Habana, enero-marzo de 1999), 21-49.

Da Cunha, Euclides. "À margem da história". Amazônia: Um paraíso perdido. Sao Paulo: Valer, 2003. 29-184.

Enkvist, Inger. "Casement, Orwell, Koestler y El sueño del celta de Vargas Llosa". La ilustración liberal. Revista española y americana. 2012.

Faulhaber, Priscila. O lago dos Espelhos. Etnografía do saber sobre a frontera em Tefé/Amazonas. Belém: Museu Paraense Emílio Goeldi, 1998.

Ferrante, Miguel Jerónimo. Seringal. Sao Paulo: Globo, 2007.

Krüger, Marcos Federico. Mito e literatura. Manaos: Valer, 2011.

Pereyra, Diomedes de. Caucho. Santiago de Chile: Nascimento, 1938.

Pizarro, Ana y Sebastián Sepúlveda. Video-grabación realizada en Belém do Pará, Brasil. Inédita, 2002.

Pizarro, Ana. Amazonía: el río tiene voces. Santiago: Fondo de Cultura Económica, 2009.

Rivera, José Eustasio. La vorágine. Caracas: Biblioteca Ayacucho, 1985.

Rama, Ángel. La ciudad letrada. Santiago: Tajamar, 2004.

Sguiglia, Eduardo. Fordlandia. Madrid: Siruela, 2004.

Silveira, Valeria Barbosa Ferreira. Universo Oral do seringueiro acreano no início do século XX: discurso é memoria. Tesis de Maestría, Universidad Federal do Acre, Rio Branco, marzo, 2011.

Vargas Llosa, Mario. El sueño del celta. Madrid: Alfaguara, 2010. 